\title{
Moving and Growing Together - Delivering Education in the New Millennium
}

\section{Renay Buchanan \\ Central Queensland University, Rockhampton, Queensland, Australia}

\author{
r.buchanan@equ.edu.aty
}

\section{Abstract}

This paper describes the challenges experienced by Academics and Instructional Designers when creating quality, innovative and accessible educational materials for the University sector in 2001 and beyond.

These two roles, which play a crucial part in the development and delivery of the new educational experience, are vital to the success of the student and ultimately, the University. Are we exploiting these roles to their full potential? It is currently the trend to place the burden of the instructional design, along with the plethora of other tasks, on the academic due to the lack of investment in instructional design and teamwork.

Is the demand to create fast, easy and inexpensive courses now resting predominantly on academics when their main role should be as a content expert and not instructional designer? Are we getting it right? Can we do it better?

Keywords : Instructional design, Education, Innovation, Delivering education, Academic, Workloads.

\section{Background}

In his virtual paper Otto Peters (1997, II 4) describes the revolution of distance education from its face-toface origin as one that lead to "a complete change in teaching and learning methods [that] could not have been more radical: beforehand everything on the teaching side has been in a single hand, now there was division of labor."

Similar to the move in geographical location from face-to-face teaching to distance education is the move from paper-based materials to the use of online or multi-media materials. This change has added new skills to the already complex and challenging task of 'single handedly' creating, maintaining and delivering educational materials. Are there specialist skills involved in creating, maintaining and delivering education through these new media or it is a core skill that every academic should acquire and be proficient at in their normal working scope? We must be watchful not to overburden any one group with the requirement to posses simultaneous, varied and complex skills that are not core to their position or that are transient in nature.

Has the higher education system taken note of the immense change that has occurred in academia and sought to change the structure of the way we do things to take into consideration this new factor? It

Material published as part of these proceedings, either on-line or in print, is copyrighted by Informing Science. Permission to make digital or paper copy of part or all of these works for personal or classroom use is granted without fee provided that the copies are not made or distributed for profit or commercial advantage AND that copies 1) bear this notice in full and 2) give the full citation on the first page. It is permissible to abstract these works so long as credit is given. To copy in all other cases or to republish or to post on a server or to redistribute to lists requires specific permission from the publisher at[Publisher@Informingscience.org seems to me that we have not responded to this challenge to a large enough extent. In many cases, technology has simply been seen as 'a different way to do the same thing', so it doesn't really add complexity or change the way we do things. Does it?

When distance education made its mark and was integrated into many large University systems it 
was recognised, by some, that it was "obvious that distance teaching at this period is to be regarded as a structurally fundamentally different system of teaching and learning” (Peters, 1997, If 5).

But in reality was anything or enough done to smoothly introduce this new dimension in learning to both the student and the teacher? Did the infrastructure change and grow to meet the new demands placed on it by the newly accessible education for all, regardless of geographical location? Did the universities instigate an across the board staff training and development scheme to allow staff to acquire the knowledge required to use this new medium to provide a high quality distance education environment for remote learners?

Have things changed or improved? We surfed the wave of the burgeoning print-based distance education only to be hit by another huge wave of transformation with the introduction of information technology. How are we coping? Are we coping? As universities, as academics, as instructional designers?

\section{Discussion}

In 1997 Otto Peters described the nature of this new form of large university industrialised teaching as "the development of courses on a basis of the division of labour and through the cooperation of specialists is extremely important because high quality material is created which is pedagogically suitable, reflects the latest levels of research and is presented particularly effectively."

Peters (1997) went on to describe the era of post-industrial teaching and learning which changed the equation of division of labour and decentralisation which had supported the 'classical course development teams' to that of a taskforce approach where teams are created and dissolved based on a perceived need to teach courses of relevance and demand. This was a significant change from the classical Course-team approach where many skilled personnel from specialised fields worked together with the support of their peers to collectively create educational materials. The new taskforce approach sees a limited number of professionals collected together for rapid course development. Due to time restrictions and deadlines this group is usually composed of content experts only who created the content rapidly and then handed it to editors and instructional designers for a cursory look and a 'wave of the magic wand' to transform it into educationally sound material suitable for the chosen distribution media and technology. Instructional designers started at the end of the process.

Taskforce members were called upon to bring both academic and technical expertise to the team. Peters $(1997$, II 21) commented, "it is no longer expected that participants in course development are specialised experts but that they are in possession of broad and multi-faceted competence."

The question that arises from this is when did the content experts gain the skills and knowledge to implement and stay current with the technological advances in instructional design?

Peters (1997, II 21) concluded that the academic content experts "are now responsible for everything to do with their courses, not just for planning and design, but also for production, distribution, evaluation and continuous course care". It does not seem feasible to support in the long term a system where staff perform so many different activities that their work is fragmented to such a degree that extended periods of focused work are not possible.

Peters (1997, II 26) predicted "commercial organisers of distance education will not wish to do without the economic advantages of the mass-production of standardised distance education courses and will probably adhere to them". This has led to the continual addition of tasks for higher education and not the suggested restructure of processes needed to cope with the new challenges. This sentiment is echoed by Farhad Saba in his interview with Jeffery Young (2001) for the Chronicle of Higher Education in which he stated, "the latest wave of distance education effort is doomed to fail unless colleges and universities drastically restructure themselves to take better advantage of information technology". 
Taylor (2001) reiterated the essential nature of organisational change by commenting that "to survive the transition from the Industrial to the Information Age organisations would need to change from rigid, formula-driven entities to organisations that were 'fast, flexible and fluid' - adjectives not typically used to describe the salient features of Universities".

Moore and Kearsley describe two different models :

... designing and teaching a distance education course should, and typically does, involve a team effort. The size of the team may be small, with as few as 2 individuals (the author-editor model) or may be a large group of 20 or more people (the course team model). The size and nature of the team depends on the scale of the course as well as the nature and level of the distance education institution involved. (Moore \& Kearsley 1996, p.104)

They describe the author-editor model as one commonly used to design and develop independent study programs with a typical example being correspondence courses (Moore \& Kearsley, 1996). This model is typical of small to medium sized distance education providers which would cover most of the distance education institutions in Australia. Small-scale production, for groups of 50 students per annum, requires low production costs so designers and editors are used only to fix inadequate materials and to assist new academics with materials creation.

The UK Open University (UKOU) were early pioneers and adopters of the Course-team model where teams consisted of a number of specialists who had a unique skill to contribute to the group. The team could be formed from a pool of content experts, technical experts (editors, graphic artists, instructional designers, producers, etc.) and administrative staff and be chaired by a senior academic. These teams recognised that each team member had a significant role to play in the complex business of course creation.

These 'megauniversities' can justify large development teams due to programs with enrolments of 5000+ students per annum. The Author-editor model can be responsive, producing a course quickly, but materials often present problems for students and need more intensive technical support and active teacher support if withdrawal/failure rates are to be kept to a minimum. However this model of low development costs and high support input can be efficient for small numbers of student in content areas that frequently change.

The Course-team model can result in 'standalone' materials which are intelligible to diverse student groups, reducing the need for interaction to occasions where dialogue is pedagogically essential. However, the high cost of production often needs to be amortized over many years. This model is efficient where content is stable and numbers are large.

What Moore and Kearsley (1996) stress is missing from the 'author + editor = course' model is the instructional design needed to produce quality and effective courses. This leaves the design job to the editor who is in the position of trying to convince the author (content expert) of the merits of designing curriculum to take into account key learning objectives and outcomes. From the eyes of an academic myself, I feel they capture the relationship very well when they state, "sometimes an editor can achieve these ends, but in real life editors are outranked by authors, and the author's will usually prevails" (Moore \& Kearsley 1996, p.105).

The instructional designer was included in the production process at the tail end to 'cast an eye' over the materials to see if they were acceptable or in some cases 'wave their magic wand' and create educationally sound materials from content. Over the years the developments in courses and technology have seen them move from the end of the process to specialised and individualised projects where their expertise would be called upon in the planning phase to assist in the creation of educational models and/or materials. This allocation to projects meant that the talents of the instructional designer were no longer available to support teaching staff on an adhoc basis whatever the issue or problem. Instructional designers became 
team members of select projects or would be left out of important projects altogether for fear that they would tell the academics 'how it should be done'.

This misconception of the role of instructional designers as managers rather than consultants has led to an increasing divide in the teamwork relationship between themselves and academics and has also lead to increased workloads for academics who are not able or willing to request the services of instructional designer to assist in the creation of materials. Without the involvement of the instructional designer, materials did not reach their full potential and were not being developed and trialled in new and innovative ways to reach new audiences via alternative media.

This in turn led to the call for more instructional designer support, but the number of instructional designers has failed to increase in line with the workload, so that the end result was a transfer of that workload to the academic authors. If we now wanted to change this status so that we provided instructional design support for all major developments we would be severely lacking in instructional design experts to satisfy demand. So the work would fall back onto the academics. And the circle continues.

Moore and Kearsley (1996) pointed out the strengths and weaknesses of each model.

\begin{tabular}{|c|c|c|}
\hline & Author-Editor & Course Team \\
\hline Strengths & $\begin{array}{l}\text { Very cost-effective } \\
\text { Minimal human resources } \\
\text { Quick development and modi- } \\
\text { fication }\end{array}$ & $\begin{array}{l}\text { Many experts in various areas } \\
\text { Complete and effective course } \\
\text { materials } \\
\text { Multiple media (usually) }\end{array}$ \\
\hline Weaknesses & $\begin{array}{l}\text { No instructional design input } \\
\text { Single expert content } \\
\text { Usually a single medium (with } \\
\text { maybe one supportive medium) }\end{array}$ & $\begin{array}{l}\text { Labour intensive } \\
* \text { Expensive } \\
* \text { Lengthy development time }\end{array}$ \\
\hline
\end{tabular}

\section{Table 1: Materials development models}

When we compare these two models to what is required today we find that we are currently trying to achieve the 'Strengths' of both models. At what cost? If we could create a hybrid of these two models that resulted in a workable model under which we can design and develop new courses to meet the new sets of demands placed upon us by this rapidly changing educational environment, then we would be one step closer to restructuring the way we do things to create a more effective and cost-efficient system.

Currently, we are trying to do more jobs then we have the expertise or time for. We are a 'jack-of-alltrades' in an increasingly competitive and rapidly changing market.

As Farhad Saba aptly put it in an interview with Jeffery Young (2001), "the University is saying, 'I have a deal for you. You are now standing in front of the classroom lecturing. Now I'm going to ask you to create an instructional system and put it online.' What kind of a deal is that? Are you helping me? Are you giving me a higher salary? Are you giving me free time?"

Using my own experience as an academic working at the Central Queensland University (CQU) within the Faculty of Informatics and Communication as an example, I have taken the attributes represented in Table 1 (above) and rearranged them to reflect the current demands of my situation. The result is a cocktail of the attributes of the Author-editor model and the Course-team model which is potentially lethal to both the health and well-being of the academics and the reputation and viability of the host institution. 
In Table 2 (below) I have listed the 'Current Needs' of the University when creating course materials and also 'Weaknesses' that exist in the present system for course and materials development.

\begin{tabular}{|c|c|c|}
\hline & Current Needs & Weaknesses \\
\hline $\begin{array}{l}\text { Author- } \\
\text { Editor }\end{array}$ & $\begin{array}{l}\text { Cost-effective } \\
\text { Minimal human resources } \\
\text { Quick development and modifi- } \\
\text { cation } \\
\text { Rapidly changing content }\end{array}$ & $\begin{array}{l}\text { Incomplete/non-comprehensive } \\
\text { course materials } \\
\text { No instructional design input } \\
\text { Development time usually means } \\
\text { limited multi-media } \\
\text { Single expert content }\end{array}$ \\
\hline $\begin{array}{l}\text { Course } \\
\text { Team }\end{array}$ & $\begin{array}{l}\text { Multiple media (usually) } \\
\text { Large student numbers } \\
\text { Complete and effective course } \\
\text { materials }\end{array}$ & $\begin{array}{l}\text { Lack of specialised experts } \\
* \text { Labour intensive } \\
* \text { Expensive } \\
* \text { Lengthy development time } \\
* \text { No long-term use }\end{array}$ \\
\hline
\end{tabular}

Table 2: An example of the current situation

The current demand for courses to be cost-effective and use the minimum of human resources stemmed from a reduction in per capita funding to universities from the government, a reduction in the numbers of academic staff in most universities and the increase in student:staff ratio. At CQU the number of students enrolled in courses owned by the Faculty of Informatics and Communication rose from 16,651 in 1998 to 18,424 in 1999 to 25,746 in 2000 and 38,216 in 2001.

This was occurring at the same time as there was an increase in demand to provide courses in more locations and different modes (internal/external/flexible/online, etc.). Compounding this demand was the expectation that these courses would be delivered to a more diverse group of students (domestic and international) using resource-based methods of delivery utilising new technology and providing greater interactivity.

Depending on the discipline, the content of a course may be a rapidly changing area or a relatively static one. Still a central requirement that remains volatile is the consumers' demand for more access to information, more interaction over distance, and richer learning environments to cater for the variety of learning styles found in increasingly diverse student populations. Many of the learning activities that could not be represented in the written word of historical text-based education are now possible through technology and multi-media. While new communication and information technologies increase pedagogical options, movement towards increased student fees and full cost recovery for programs increases a student's expectation that technology will be used, and will be used well. An increasing number of learners want the opportunity to learn in their chosen style and not in an inflexible static environment.

The growing demand for online and multi-media resources has led to the expansion (or should I say explosion) of resources now required for every course. This leaves the academic with a workload consisting of not just being the content expert, but instructional designer, multi-media developer, graphic artist and editor. At the same time new copyright legislation and quality assurance requirements introduce complex rules and procedures for educational use of materials and learning outcomes. As technology pervades our society the first place it becomes a basic requirement is within our teaching and learning arenas. From primary school to tertiary education, the public is demanding that they be taught how to interact with this 
new technology society because technological literacy is seen as essential for future employment and interactions. As universities respond to this demand we see academics being asked to take on multiple roles, not just that of the content expert.

But technology is an interesting phenomenon. We have tried so hard to make it 'user friendly' that now we consider it to be an essential and 'easy' add-on. It doesn't add complexity; it reduces it. It makes it easier to do things; not harder. It makes things quicker; not slower. It makes it more cost-effective; not more expensive. It's not changing what we do; it's helping us do it. Is it?

We seem to have been seduced by this technology era without taking the time to work out what it really means for us and how it is changing everyday things about our lives and our future.

But who am I to stop the flood of technology? Just one.

To ride the wave of technology I must learn to do things 'smarter'. This is a nice concept but in education, smarter can sometimes really mean slimmer and quicker. It means don't do as much work, but get the job done. It means added features but not added complexity. To me it just doesn't add up.

The Faculty of Informatics and Communication at CQU has been wrestling with this dilemma for quite a while now with increases in the number of campuses and modes of study resulting in a huge increase in student numbers each year for the past 3 years $(1999,2000,2001)$ with very little or no increase in staff until the start of 2002.

The School of Computing and Information Systems within the Faculty of Informatics and Communication has started a trial, which will see the implementation of four Academic Discipline Teams (ADT). The word 'academic' refers to the focus of the team and not to the role of team members. These teams are to be a home for the academic discipline of a chosen area and will be responsible for the coordination and development of multiple courses or course streams.

In this trial the teams will be formed on a voluntary basis with staff members of the school choosing to be involved in one or more teams depending on their area of expertise. The team's core will be composed of content experts, instructional designer/s, technical staff, administrative staff and a library liaison. On an as-needed basis, the team will invite other professionals from within and outside the University to participate in team activities. It is envisaged that typically these people will be drawn from industry, professional associations, the community, government bodies and other areas of the University.

The ADT's focus will be to ensure that the courses within their discipline area stay in step with the degree/s in which they participate and the industry in which they have their home. The team will also be responsible for providing focus for the development of discipline itself and also for its integration with the other discipline teams, from within the school and faculty and between faculties where cross-discipline activity occurs.

The suggested model (Table 3) for these ADT's (which by no means contains an exhaustive list) attempts to incorporate the strengths of both the Author-editor model and the Course-team model while recognising that there must be a trade-off between achieving all your strengths and limiting the impact of your weaknesses. 


\begin{tabular}{|c|c|}
\hline & Suggested ADT Model \\
\hline Strengths & $\begin{array}{l}\text { Team-based approach } \\
\text { Unified direction for multiple (related) courses } \\
\text { Team ownership of courses and resources } \\
\text { Cost-effective based on income } \\
\text { Minimum core of human resources } \\
\text { On-call pool of human resources (short periods of involvement) } \\
\text { months) } \\
\text { Feasible time period for development and modification (one term/6 } \\
\text {. Cycling of duties (skills sets, focus, tasks) } \\
\text { Multiple media included (specialist experts) } \\
\text { prehensive instructors' manual) } \\
\text { Complete and effective course materials (through planning and devel- } \\
\text { opment and external input) } \\
\text { Ability to support rapid development of materials (if needed) } \\
\text { Ability to integrate information literacy and information technology } \\
\text { Ability to respond quickly and effectively to evaluation, feedback and } \\
\text { problems }\end{array}$ \\
\hline Weaknesses & $\begin{array}{l}\text { Expensive to start with and set up } \\
\text { * Requires a staff member to coordinate the development work } \\
\text { months) } \\
\text { * Short life span of work (which is inevitable) } \\
\text { - Current lack of teamwork skills } \\
\text { Possible lack of available external inputs } \\
\text { * Requires the majority of the academic staff in the discipline area to } \\
\text { cooperate } \\
* \text { Requires staff to take shared collegial responsibility for achieving } \\
\text { quality outcomes }\end{array}$ \\
\hline
\end{tabular}

Table 3: Suggested ADT model 
With the ever-changing nature of information technology and the plethora of information and skills that are now essential to working life and life-long education it can be an unruly educational experience that a student encounters on their journey through university.

The ADT model tries to gain the economies of scale by allowing a team of professionals to focus on a discipline area in which they can see the progression of students and education from the building blocks introduced in first year courses to the advanced topics explored in their final year. We hope the development of the discipline, as a unit will lead to a more cohesive educational experience for students. This in turn may evolve into a new and effective system for the development and growth of courses with pedagogically sound assessment and instruction methods utilising the best technology has to offer, while respecting that technology is not the answer to every problem.

\section{Conclusion}

Moore and Kearsley (1996, p.9) make the statement that "producing distance education courses involves many kinds of design expertise". This sentence can be expanded today to not only include distance education but also the production of distance, flexible and online education courses. The necessity still remains for materials to be "designed by individuals with a knowledge of the instructional principles and techniques as well as knowledge of the technology."

The team approach has been tried many times in the past and has undergone many changes to its structure, input and outputs, depending upon the demands of the organisation. Here we have no exception, the guidelines are the same as they were for distance education : "the key characteristics of most successful distance education courses is that they are designed by course teams in which many specialists work together" (Moore \& Kearsley, 1996, p.9).

Instructional designers have for many years been at the tail end of the content production process at CQU. They are there to perform the checks and the balances and every now and then they are called upon to weave their magic and create educational materials from content. The intent of the new ADT model is to include instructional design, and therefore instructional designers, in the forefront of the process, at the embryonic stage of the content, ideas and pedagogy development process. To be the consultant of paradigms and methodologies which will help the potter mould his clay to produce a majestic piece of art.

There will be resistance from some quarters of the academic circle for both the idea of ADT's and the new role of the instructional designer in assisting in the creation of courses. I can see many an academic trying to return to the old roles of Author-editor where they perceive they have more power over their content and intellectual property. But going backwards is not a way forward. As many great people have expressed "the only thing in life that is constant is change". We must change to respond to the everincreasing complexity of the higher education sector.

Are we going to continue to struggle with the increasing complexity of our workloads? Or are we able to find new ways of working together to create quality educational experiences for learners and teachers utilizing the most effective design and delivery mechanisms available to assist in the education of our students?

As Stephen Gould (1990, p209) quoted of the Hegelian and Marxists, we need to be "transformers of quantity into quality", and be able to recognise that "systems often resist change and absorb stresses to a breaking point, beyond which an additional small input may trigger a profound change of state".

\section{References}

Gould, Stephen Jay. (1990). An urchin in the storm. London : Penguin Group.

Moore, Michael G. \& Kearsley, Greg. (1996). Distance education - “A systems view”. United States of America : Wadsworth Publishing Company. 
Peters, Otto. (1997) Industrialised Teaching and Learning. Retrieved August 5, 2000, from The University of Maryland Institute for Distance Education and Carl von Ossietzky Oldenburg Center for Distance Education, Virtual Seminar on Distance Education Web site : ittp://www.umuc.edu/ide/seminar-2/peters97.htmा

Taylor, J.C. (2001). $5^{\text {th }}$ Generation Distance Education, DETYA's Higher Education Series, Report No. 40, June 2001.

Young, Jeffery R. (2001). Professor says distance education will flop unless Universities revamp themselves. Interview with Farhad Saba. Chronicle of Higher Education 47 (42).

\section{Biography}

Renay is employed at the Central Queensland University (CQU) in Australia. She has been a member of the academic community there since 1992. In this time she has taken on many roles, some being, tutor, lecturer, course coordinator, Deputy Faculty Assembly President, Acting Associate Dean (Teaching and Learning) and Acting Dean (Faculty of Informatics and Communication).

She has taken leave in this time to complete 12 months Industry Experience in her teaching area of Networks. Since returning to academia she has completed two industry certifications in this area. Presently she is finishing a 12-month secondment as an Educational (Instructional) Designer within the Division of Teaching and Learning Services (DTLS) at CQU. 